\title{
In vivo and in vitro analysis of topographic changes secondary to DSAEK venting incisions
}

This article was published in the following Dove Press journal:

Clinical Ophthalmology

24 August 201I

Number of times this article has been viewed

\author{
Majid Moshirfar \\ Monette T Lependu \\ Dane Church \\ Marcus C Neuffer \\ John A Moran Eye Center, University \\ of Utah, Salt Lake City, UT, USA
}

\begin{abstract}
Introduction: Descemet's stripping automated endothelial keratoplasty (DSAEK) venting incisions may induce irregular corneal astigmatism. The study examines in vivo and in vitro astigmatic effects of venting incisions.

Patients and methods: In vivo analysis examined eleven eyes of eleven patients who had received DSAEK with venting incisions. A chart review of the eleven eyes including assessment of pre and postoperative refraction and topography was performed. In vitro analysis examined three cadaver eyes which received topographic imaging followed by venting incisions at $4 \mathrm{~mm}, 6 \mathrm{~mm}$, and $7 \mathrm{~mm}$ optical zones. Topographic imaging was then performed again after the incisions.

Results: Postoperative topographies of eleven eyes demonstrated localized flattening at incision sites and cloverleaf pattern astigmatism. There was a significant difference in corneal irregularity measurement $(P=0.03)$, but no significant difference in shape factor or change of topographic cylinder. The cloverleaf pattern was found in cadaver eyes with incisions placed at $4 \mathrm{~mm}$ and $6 \mathrm{~mm}$ optical zones but not at the $7 \mathrm{~mm}$ zone.
\end{abstract}

Conclusion: DSAEK venting incisions can cause irregular corneal astigmatism that may affect visual outcomes. The authors recommend placement of venting incisions near the $7 \mathrm{~mm}$ optical zone.

Keywords: DSAEK, venting incisions, endothelial keratoplasty, astigmatism, endothelium, endothelial transplant

\section{Introduction}

First described by Price and Price, venting incisions are commonly used in Descemet's stripping automated endothelial keratoplasty (DSAEK) to remove fluid from the donor-recipient interface. ${ }^{1}$ A 15 -degree blade is used to make four equally spaced full thickness mid-peripheral incisions in the recipient cornea. The incisions promote donor-recipient adherence by allowing interface fluid to egress. As described in previous literature, transverse corneal incisions cause flattening on the same meridian with steepening 90 degrees away. ${ }^{2}$ The astigmatic effect of corneal venting incisions has not yet been described. This study describes the effect of corneal venting incisions from DSAEK surgery.

\section{Material and methods}

\section{In vivo}

Eleven eyes of eleven patients aged 65-81 years old who had previously received DSAEK with corneal venting incisions were examined with slit lamp biomicroscopy. 
Table I Preoperative and postoperative examination

\begin{tabular}{llllllll}
\hline Case & Age & $\begin{array}{l}\text { Months since } \\
\text { DSAEK }\end{array}$ & With phaco & $\begin{array}{l}\text { Pre-op } \\
\text { CDVA }\end{array}$ & $\begin{array}{l}\text { Post-op } \\
\text { CDVA }\end{array}$ & Pre-op MRX & Post-op MRX \\
\hline I & 73 & 6 & $\mathrm{Y}$ & $20 / 30$ & $20 / 25$ & $+1.25 \times 045$ & $+1.25 \times 106$ \\
2 & $8 \mathrm{I}$ & 6 & $\mathrm{~N}$ & $20 / 60$ & $20 / 40$ & $+1.25 \times 005$ & $+2.25 \times 015$ \\
3 & 76 & 6 & $\mathrm{Y}$ & $20 / 70$ & $20 / 50$ & $+2.25 \times 166$ & $+2.25 \times 163$ \\
4 & 68 & 6 & $\mathrm{Y}$ & $20 / 40$ & $20 / 20$ & $+2.50 \times 020$ & $+2.75 \times 035$ \\
5 & 72 & 6 & $\mathrm{~N}$ & $20 / 200$ & $20 / 20$ & $+2.00 \times 027$ & $+1.50 \times 155$ \\
6 & 74 & 6 & $\mathrm{~N}$ & $20 / 60$ & $20 / 40$ & $+1.50 \times 105$ & $+0.75 \times 107$ \\
7 & 65 & 6 & $\mathrm{Y}$ & $20 / 40$ & $20 / 30$ & $+1.00 \times 178$ & $+0.50 \times 175$ \\
8 & 70 & 6 & $\mathrm{Y}$ & $20 / 200$ & $20 / 30$ & $+3.25 \times 095$ & $+0.50 \times 120$ \\
9 & 70 & $\mathrm{I}$ & $\mathrm{Y}$ & $20 / 50$ & $20 / 30$ & $+0.25 \times 015$ & $+0.75 \times 002$ \\
10 & $8 \mathrm{Y}$ & $\mathrm{I}$ & $\mathrm{Y}$ & $20 / 60$ & $20 / 30$ & $+2.50 \times 165$ & $+1.50 \times 015$ \\
$\mathrm{II}$ & 73 & 24 & $\mathrm{~N}$ & $20 / 50$ & $20 / 20$ & 0 & $+0.50 \times 110$ \\
Mean $(P$ value* $)$ & 74 & 8.5 & & $20 / 64$ & $20 / 29(0.003)$ & $+1.61 \times 82$ & $+1.32(0.23) \times 91(0.75)$ \\
\hline
\end{tabular}

Note: $* P$ value calculated from paired $t$-test.

Abbreviations: Pre-op, preoperative; Post-op, postoperative; CDVA, corrected distance visual acuity; Cyl, cylinder; DSAEK, Descemet's stripping automated endothelial keratoplasty; MRX, manifest refraction; phaco, phacoemulsification of cataract.

The locations of the incisions were identified and corresponding incision locations were noted on the patients' topographies. Preoperative and postoperative visual acuity, refraction, and topographies (Atlas Corneal Topographer, Carl Zeiss Meditec, Inc, Dublin, CA) were compared.

All eyes had received DSAEK with a $3.5 \mathrm{~mm}$ wound and superior and nasal paracentesis incisions. Midperipheral, transverse venting incisions were made after stripping of Descemet's membrane and while the anterior chamber was still inflated with viscoelastic. Incisions were formed with a $1.8 \mathrm{~mm}$ diamond blade. The dimension of the endothelial donor button in DSAEK was between 8 and $8.50 \mathrm{~mm}$. Eight of the eleven eyes had cataract surgery at the time of DSAEK. Seven eyes received monofocal lenses and one eye (case 8 ) received a toric lens. No limbal relaxing incisions were performed.

\section{In vitro}

Corneal topography was performed on three whole cadaver globes donated for research (Utah Lions Eye Bank, Salt Lake
City, UT). Before topographic imaging, corneal epithelium was removed and the globes were rinsed with Balanced Saline Solution (BSS, Alcon, Fort Worth, TX). The superior sclera was marked to ensure correct positioning. After initial imaging, the globes were placed under a surgical microscope, the center of the cornea identified, and four $1.5 \mathrm{~mm}$ wide venting incisions were made with a 15 degree blade (Sharpoint, Surgical Specialties Corporation, Reading, PA). Calipers were used to measure the distance from the center of the cornea. Venting incisions were made at the $4 \mathrm{~mm}$ optical zone on one eye, $6 \mathrm{~mm}$ on the next, and $7 \mathrm{~mm}$ on the last eye. Topographic imaging was repeated and venting incision locations were identified on the topography map.

\section{Results}

Preoperative diagnosis of all eleven eyes was Fuch's endothelial dystrophy. None of the eyes had advanced glaucoma or macular degeneration. The average time since DSAEK was 8.5 months with majority of eyes being
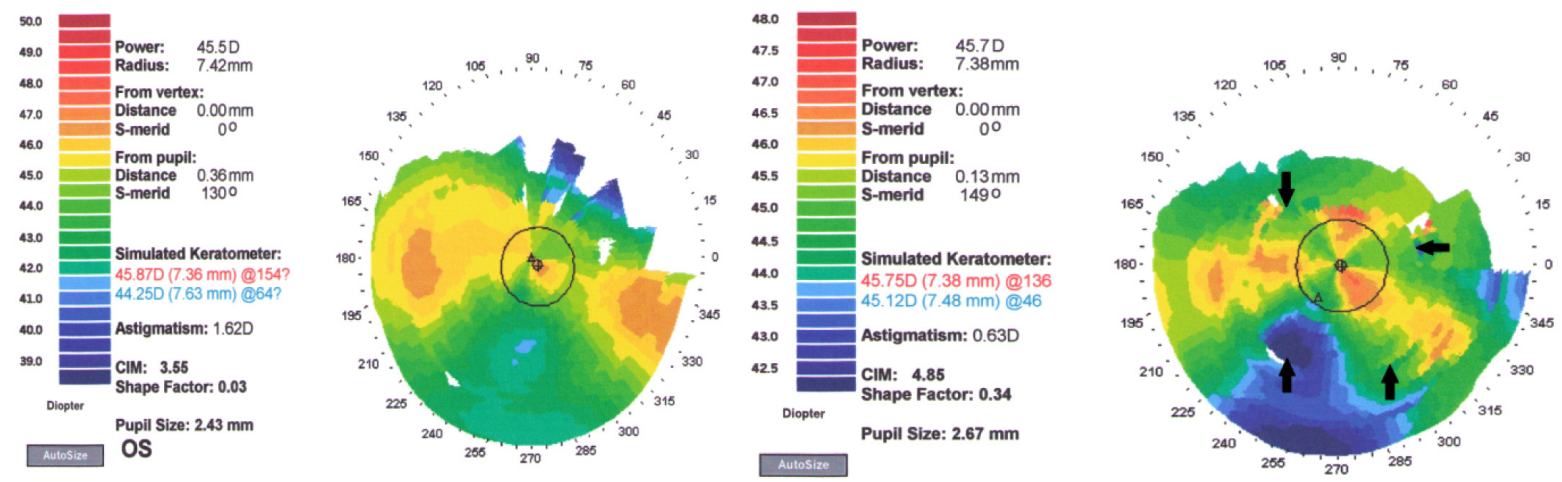

Figure I Case 6: Preoperative and 6-month postoperative topography with venting incision locations (arrows) and clover pattern astigmatism. 

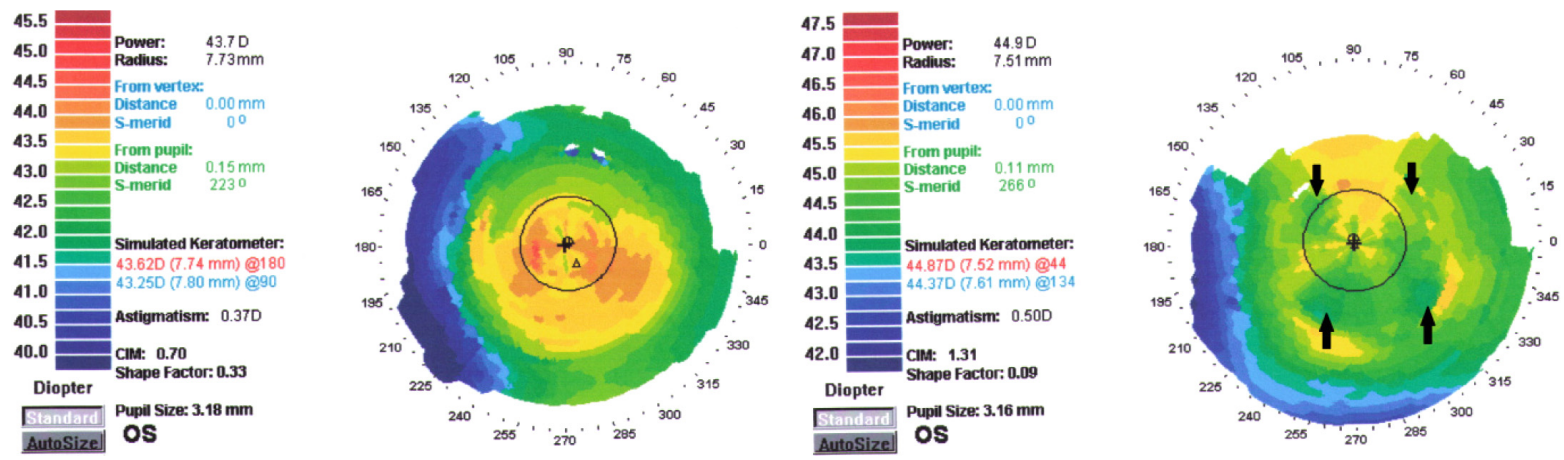

Figure 2 Case 7: Preoperative and 6-month postoperative topography with venting incision locations (arrows) and clover pattern astigmatism.

6 months since DSAEK. All eyes had improved visual acuity and three achieved 20/20 on the Snellen chart. There was no significant difference between preoperative and postoperative manifest cylinder $(P=0.23)$ or axis $(P=0.75)$ with eight of the eleven eyes having $<1.00 \mathrm{D}$ of change. Cases 2,8 , and 10 had $\geq 1.00 \mathrm{D}$ change in manifest cylinder (Table 1).

Comparison of preoperative and postoperative topography demonstrated localized flattening at incision sites and cloverleaf pattern astigmatism (Figures 1 and 2). Further topography evaluation revealed a significant difference between pre and postoperative corneal irregularity measurement (CIM) $(P=0.03)$; but no difference in shape factor $(P=0.17)$, topographic cylinder $(P=0.49)$, or change in axis $(P=0.72$; Table 2$)$. Comparing the degree of change in CIM ( $\triangle$ CIM) with optical zone placement of the incisions demonstrated that the increase in CIM became less the farther the incisions were placed from the optical center (Figure 3).
A cloverleaf pattern was also found in the cadaver eyes which had incisions at $4 \mathrm{~mm}$ and $6 \mathrm{~mm}$ optical zones (Figure 4A and B). No significant irregular flattening was appreciated in the eye that had incisions at the $7 \mathrm{~mm}$ zone (Figure 4C). As with the in vivo analysis, the CIM also increased on post venting incision topography with an increase of 0.69 and 1.75 in the globes with $4 \mathrm{~mm}$ and $6 \mathrm{~mm}$ optical zone incisions respectively. The increase in CIM was less $(0.03)$ in the eye with incisions at $7 \mathrm{~mm}$.

\section{Discussion}

A growing question among DSAEK surgeons is why some patients are not achieving 20/20 vision even months after surgery when grafts appear clear and no lens or retinal pathology exists. Described possible impediments to achieving 20/20 vision are interface haze $\mathrm{e}^{3-5}$ and posterior higher order aberrations ${ }^{6}$ of the cornea. We suggest that irregular anterior astigmatism is another possible cause for patients' suboptimal vision after DSAEK.

Table 2 Preoperative and postoperative topography data

\begin{tabular}{|c|c|c|c|c|c|c|c|c|c|c|}
\hline Case & $\begin{array}{l}\text { Pre-op } \\
\text { CIM }\end{array}$ & $\begin{array}{l}\text { Post-op } \\
\text { CIM }\end{array}$ & $\begin{array}{l}\text { Pre-op } \\
\text { shape } \\
\text { factor }\end{array}$ & $\begin{array}{l}\text { Post-op } \\
\text { shape } \\
\text { factor }\end{array}$ & $\begin{array}{l}\text { Venting } \\
\text { Incision } \\
\text { OZ (mm) }\end{array}$ & $\begin{array}{l}\text { Endothelial } \\
\text { button } \\
\text { diameter } \\
(\mathrm{mm})\end{array}$ & Pre-op K & $\begin{array}{l}\text { Pre-op } \\
\text { steep axis }\end{array}$ & Post-op K & $\begin{array}{l}\text { Post-op } \\
\text { steep axis }\end{array}$ \\
\hline I & 1.48 & 1.85 & 0.29 & 0.38 & 6.5 & 8.25 & $43.50 / 44.75$ & 63 & $43.00 / 43.62$ & 54 \\
\hline 2 & 2 & 2.95 & 0.23 & 0.3 & 5.5 & 8 & $43.25 / 44.12$ & 146 & $42.00 / 43.50$ & 50 \\
\hline 3 & 0.65 & 1.32 & 0.25 & 0.29 & 6 & 8.25 & $44.37 / 46.87$ & 12 & $44.12 / 47.00$ & 172 \\
\hline 4 & 1.23 & $2.6 I$ & 0.28 & $0.7 I$ & 6 & 8.5 & $45.12 / 47.12$ & 46 & $44.25 / 47.12$ & 56 \\
\hline 5 & 2.2 & 1.9 & 0.5 & 0.82 & 7 & 8.25 & $41.25 / 45.50$ & 20 & $41.40 / 44.87$ & 124 \\
\hline 6 & 3.55 & 4.85 & 0.03 & 0.34 & 5.5 & 8.25 & $44.25 / 45.87$ & 154 & $45.12 / 45.75$ & 136 \\
\hline 7 & 0.7 & I.31 & 0.33 & 0.09 & 5.8 & 8.25 & $43.25 / 45.62$ & 180 & $44.37 / 44.87$ & 44 \\
\hline 8 & 1.62 & 1.81 & 0.64 & 0.61 & 6 & 8.25 & $42.50 / 44.50$ & 94 & $43.37 / 45.87$ & 108 \\
\hline 9 & 0.65 & 2.32 & 0.15 & 0.15 & 5.5 & 8.25 & $44.62 / 45.87$ & 50 & $44.62 / 45.12$ & 152 \\
\hline 10 & 1.59 & 2.4 & 0.25 & 0.21 & 5.5 & 8 & $47.12 / 48.25$ & 72 & $45.87 / 47.25$ & 32 \\
\hline II & 0.83 & 1.07 & 0.01 & 0.02 & 5.5 & 8.25 & $45.50 / 46.62$ & 84 & $45.25 / 46.12$ & 100 \\
\hline $\begin{array}{l}\text { Mean } \\
(P \text { value* })\end{array}$ & 1.5 & $\begin{array}{l}2.22 \\
(0.00)\end{array}$ & 0.27 & $\begin{array}{l}0.36 \\
(0.17)\end{array}$ & 5.9 & 8.23 & $44.07 / 45.74$ & 84 & $\begin{array}{l}43.98 / 45.59 \\
(0.49)\end{array}$ & $\begin{array}{l}94 \\
(0.72)\end{array}$ \\
\hline
\end{tabular}

Note: ${ }^{*} P$ value calculated from paired $t$-test.

Abbreviations: Pre-op, preoperative; Post-op, postoperative; CIM, corneal irregularity measurement; cyl, cylinder; K, keratometry; OZ, optical zone. 


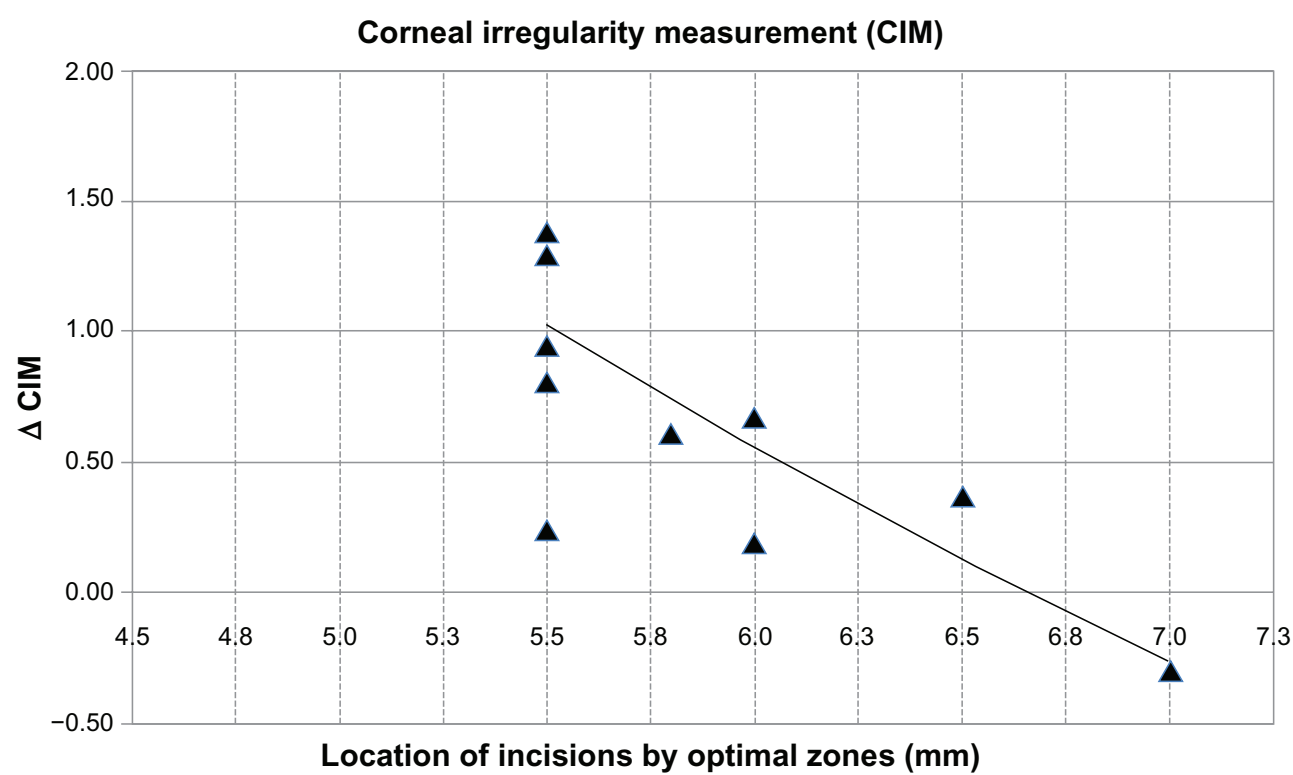

Figure 3 Comparing $\Delta$ CIM with the location of the venting incisions demonstrates a decrease in $\Delta$ CIM as the optical zone location increases.
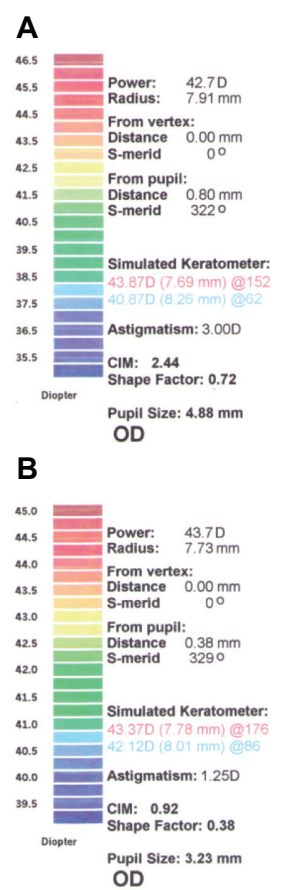

C

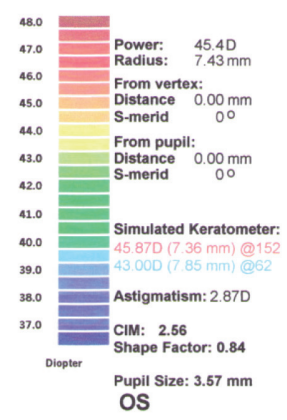

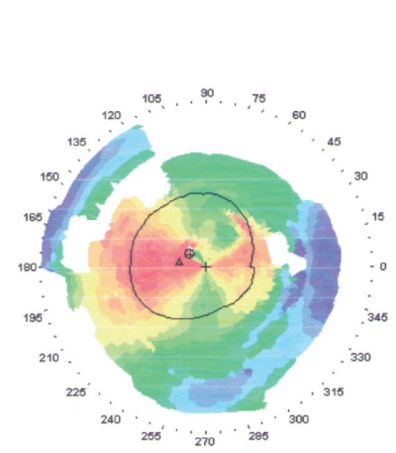
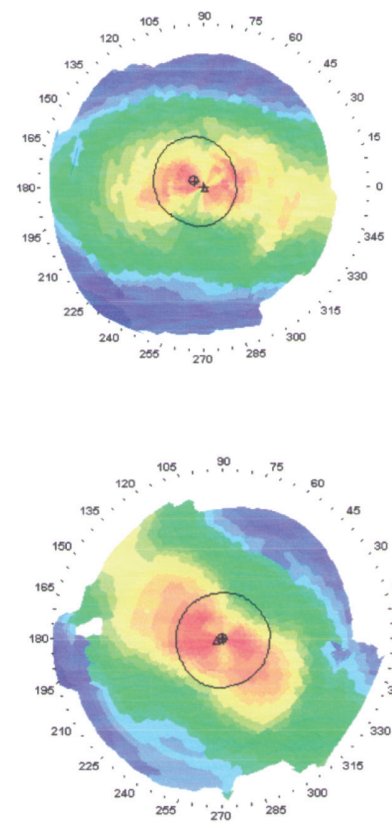
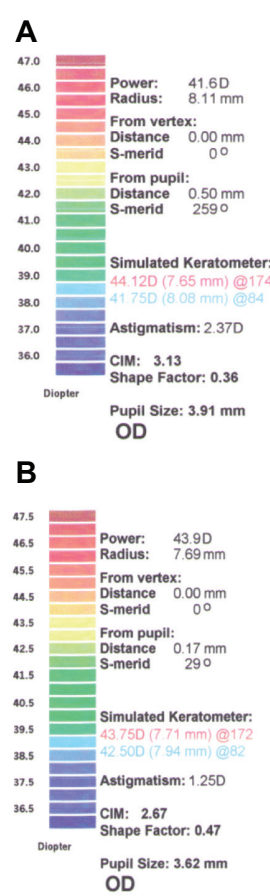

C

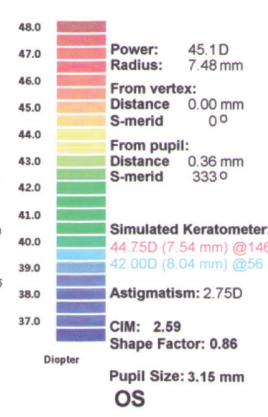

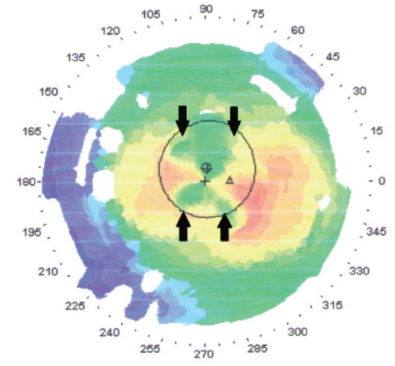
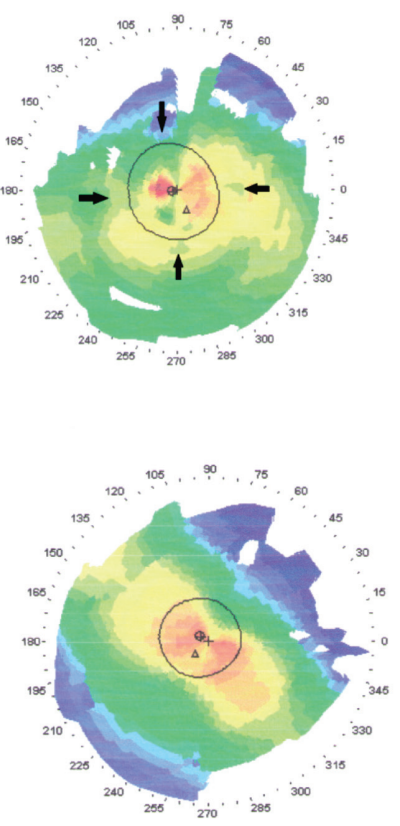

Figure 4 Cadaver eyes with pre (left column) and post (right column) venting incisions topography. (A) Incisions at $4 \mathrm{~mm}$ optical zone. (B) Incisions at $6 \mathrm{~mm}$ optical zone. (C) Incisions at $7 \mathrm{~mm}$ optical zone. 
In reviewing pre- and postoperative topographies in eyes that underwent DSAEK, we found that venting incisions may create irregular astigmatism. Although no significant change occurred in manifest cylinder, topographic keratometry, or shape factor, there was a significant increase in CIM. CIM is a measurement representing irregularity of the corneal surface where a higher number signifies a more uneven surface or irregular astigmatism. The irregular astigmatism on these corneas appear as a cloverleaf pattern due to the localized flattening effect of the four incisions (Figures 1 and 2). In comparing the increase of CIM with optical zone placement of the incisions, we found the CIM to decrease as the optical zone placement increased (Figure 3). We were able to recreate this with cadaver eyes by placing incisions at the 4,6 , and $7 \mathrm{~mm}$ optical zones. Incisions closer to the optical center clearly induced irregular astigmatism (Figure $4 \mathrm{~A}$ and B) where incisions farther from the optical zone appeared to have less of an effect (Figure 4C). A limitation of this study is that patient best CDVA was not evaluated using a gas permeable hard contact lens. Improvement of visual acuity with fitting of such lenses may support our hypothesis concerning loss of vision secondary to irregular astigmatism.

This study is small although it easily demonstrates the astigmatic effect of venting incisions on the cornea. Another criticism is that a $1.8 \mathrm{~mm}$ diamond blade was used to create the venting incisions in the eleven eyes instead of a 15 degree blade as originally described by Price. ${ }^{1}$ A $1.8 \mathrm{~mm}$ blade, as expected, would cause more astigmatic changes on the cornea. However, with the cadaver eyes we demonstrated that a 15 degree blade, with smaller width incisions, can still have the same effect.

In conclusion, DSAEK venting incisions can induce irregular corneal astigmatism that may contribute to patients not achieving their maximum vision potential.
Incisions farther from the optical zone may have less effect, and thus venting incisions near the $7 \mathrm{~mm}$ optical zone are recommended. Smaller and fewer incisions may also induce less astigmatism and consequently be better, however, they may increase the risk of retained interface fluid. Finding the correct balance between creating effective venting incisions and avoiding induction of irregular astigmatism is important in achieving the best outcome in DSAEK. Yet, as technique in DSAEK surgery has improved, some have questioned whether venting incisions are necessary and many surgeons have discontinued the use of venting incisions in the DSEAK procedure.

\section{Acknowledgment}

Funding was received from the Research to Prevent Blindness Foundation (New York, NY).

\section{Disclosure}

The authors have no financial interests in any materials or products discussed in the manuscript or any other conflicts of interest in this work.

\section{References}

1. Price FW Jr, Price MO. Descemet's stripping with endothelial keratoplasty in 200 eyes: early challenges and techniques to enhance donor adherence. J Cataract Refract Surg. 2006;32(3):411-418.

2. Krachmer JH, Mannis MJ, Holland EJ, editors. Cornea: Surgery of the Cornea and Conjunctiva 3rd edition. Vol 2. New York: Mosby Elsevier Inc; 2011

3. Hindman HB, McCally RL, Myrowitz E, et al. Evaluation of deep lamellar endothelial keratoplasty surgery using scatterometry and wavefront analyses. Ophthalmology. 2007;114(11):2006-2012.

4. Kobayashi A, Mawatari Y, Yokogawa H, Sugiyama K. In vivo laser confocal microscopy after Descemet stripping with automated endothelial keratoplasty. Am J Ophthalmol. 2008;145(6):977-985.

5. Espana EM, Huang B. Confocal microscopy study of donor-recipient interface after Descemet's stripping with endothelial keratoplasty. $\mathrm{Br} J$ Ophthalmol. 2010;94(7):903-908.

6. Muftuoglu O, Prasher P, Bowman RW, McCulley JP, Mootha VV. Corneal higher-order aberrations after Descemet's stripping automated endothelial keratoplasty. Ophthalmology. 2010;117(5):878-884.
Clinical Ophthalmology

\section{Publish your work in this journal}

Clinical Ophthalmology is an international, peer-reviewed journal covering all subspecialties within ophthalmology. Key topics include: Optometry; Visual science; Pharmacology and drug therapy in eye diseases; Basic Sciences; Primary and Secondary eye care; Patient Safety and Quality of Care Improvements. This journal is indexed on

\section{Dovepress}

PubMed Central and CAS, and is the official journal of The Society of Clinical Ophthalmology (SCO). The manuscript management system is completely online and includes a very quick and fair peer-review system, which is all easy to use. Visit http://www.dovepress.com/ testimonials.php to read real quotes from published authors. 